\title{
SER OU NÃO SER GAY-FRIENDLY: O CASO DA BEAUTY FACTOR
}

\author{
TO BE OR NOT TO BE GAY-FRIENDLY: THE CASE OF BEAUTY FACTOR
}

Recebido em: 27/09/2017 - Aprovado em: 21/03/2018
Avaliado pelo sistema double blind review
Editor Científico: Edson Sadao Iizuka
DOI $10.13058 /$ raep.2018.v19n2.793

\section{ESTELAMARIAHOFFMANN estelamhoff@gmail.com \\ MARIA JOSÉ BARBOSA DE SOUZA \\ ANA PAULA KIELING}

Universidade do VALE do ITAJAí

\begin{abstract}
RESUMO
O presente caso de ensino objetiva oportunizar aos alunos a vivência de situações pertinentes ao contexto mercadológico a partir da análise da Beauty Factor, uma empresa de cosméticos que produz e comercializa produtos de beleza. A empresa, que figura entre as líderes de mercado no Brasil, respeita a diversidade e a dignidade humana e busca atingir diferentes segmentos por meio de novos investimentos em publicidade e propaganda. Para tal, a equipe de marketing, sob a supervisão de Maria Fernanda Coutinho, contratou uma consultora empresarial, Cristina Albuquerque, para o desenvolvimento de estratégias de mercado com foco nos consumidores homossexuais. Frente a esse objetivo, a consultora e a empresa deparam-se com um dilema: qual a melhor forma de anunciar o produto para o segmento homossexual sem desconsiderar os interesses dos segmentos atendidos pela empresa até o momento? Como instrumento de ensino, o caso foi desenvolvido para uso em cursos de graduação e pós-graduação em Administração de Empresas, Marketing e Publicidade e Propaganda. O debate inclui temas como estratégia de marketing, segmentação de mercado e publicidade e propaganda a serem abordados nas disciplinas de Administração Mercadológica, Gestão de Marketing, Estratégias de Comunicação em Marketing e Segmentação de Mercado.

Palavras-chave: Gestão de Marketing. Segmentação de Mercado. Estratégias de Comunicação. Segmento Homossexual.
\end{abstract}

\begin{abstract}
The present teaching case aims to provide students with the experience of situations related to the marketing context, based on the analysis of Beauty Factor, a cosmetics company that produces and sells beauty products. The company, which is among the market leaders in the country, respects diversity and human dignity and seeks to reach different segments through new investments in marketing and advertising. For this reason, their marketing team, under the supervision of Maria Fernanda Coutinho, has hired a business consultant, Cristina Albuquerque, to develop market strategies focused on homosexual consumers. With this goal, the consultant and the company face a dilemma: what is the best way to advertise the product for the homosexual segment without disregarding the interests of other segments served by the company so far? As a teaching tool, the case was developed to be used in undergraduate and postgraduate courses in Business Administration, Marketing and Advertising. The debate includes topics such as marketing strategies, market segmentation and advertising, to be addressed in Marketing Management, Strategies of Marketing Communication and Market Segmentation.

Keywords: Marketing Management. Market Segmentation. Communication Strategies. Homosexual Segment.
\end{abstract}




\section{INTRODUÇÃO}

Cristina Albuquerque sempre foi uma profissional movida a desafios. Formada em Administração com MBA na área estratégica, ela é o retrato de uma profissional de sucesso. Durante muito tempo atuou como consultora para empresas multinacionais e, com isso, vivenciou muitas mudanças no mercado.

Recentemente, foi convidada por Maria Fernanda Coutinho, executiva de marketing da Beauty Factor - uma empresa multinacional de cosméticos -, para desenvolver novas estratégias de comunicação de marketing na campanha do Dia dos Namorados da marca. O principal desafio da empresa naquele momento era prospectar um novo mercado: o público homossexual.

Numa manhã de março de 2017, Cristina olhava atenta para a tela de seu computador e refletia sobre os dados que acabara de coletar. O toque do celular interrompeu seus pensamentos:

- Bom dia, Cristina. Tudo bem? Aqui quem fala é a Maria Fernanda Coutinho, da Beauty Factor. Gostaria de confirmar a data da nossa reunião. Como temos pouco tempo para a produção da campanha do Dia dos Namorados, será que é possível discutirmos as ideias para o novo posicionamento amanhã, à tarde?

- Bom dia, Maria Fernanda. É possível sim e concordo, temos urgência. Estava trabalhando nisso agora mesmo. Acredito que até amanhã consigo fazer todos os levantamentos necessários para discutirmos com a equipe.

A conversa prosseguiu por mais alguns minutos e, logo, Cristina estava imersa nas informações que acabara de encontrar. Ela sabia o quanto Maria Fernanda estava decidida a desenvolver um novo posicionamento para a empresa, mas sabia também, que havia muita resistência por parte de alguns executivos da Beauty Factor.

A consultora estava ciente da dedicação exigida por esse projeto e, por esse motivo, buscou um apanhado de informações consistentes sobre 
o mercado consumidor homossexual no Brasil. Cristina compreendia que esse era um mercado promissor, mas estava preocupada com a dimensão do preconceito existente na sociedade brasileira. Ela analisou campanhas de diversas empresas que já haviam abordado o tema e sua repercussão tanto nas redes sociais quanto em sites de notícias. Assim, percebeu o quanto ainda era delicado associar uma marca com o segmento homossexual. Diante disso e objetivando encontrar uma solução viável para a empresa, perguntava-se: qual a melhor forma de anunciar o produto para o segmento homossexual sem ferir os interesses dos segmentos atendidos pela empresa até o momento? 


\section{A BEAUTY FACTOR}

A empresa Beauty Factor surgiu no mercado de cosméticos no ano de 2001, no interior de São Paulo, ganhando alcance e reconhecimento internacional com o passar dos anos. Foi criada por Benedita Souza, uma empreendedora que começou a desenvolver produtos para atender as suas clientes no salão que dividia com uma sócia em seu bairro. No fim dos anos 90 , Benedita não encontrava cosméticos para cabelo que gerassem os efeitos desejados ou tivessem fragrâncias que lhe agradassem e, por essa razão, começou a manipular seus próprios produtos em casa para suprir uma necessidade de seu pequeno negócio.

Com o tempo, percebeu que a procura por seus xampus, condicionadores e máscaras restauradoras se ampliava cada vez mais. Suas clientes começaram a questionar se ela não tinha os produtos para venda, pois queriam continuar o tratamento em suas residências. Esse foi o ponto da virada para Benedita, que, junto com o marido, decidiu abandonar a vida de cabeleireira um ano depois e empreender no ramo de cosméticos. Assim nascia a Beauty Factor, de forma tímida, em uma linha de produção improvisada na garagem da casa de Benedita.

Devido à qualidade dos produtos, logo as vendas se expandiram e, em 2002, foi preciso investir em uma sede própria e funcionários. Dois anos depois, em 2004, a empresa já contava com mais de 50 colaboradores e, desde então, não parou de crescer. Em 2007, Benedita e seu filho Jorge Souza, então presidente da companhia, decidiram investir em novos produtos, além do trio capilar que era vendido desde o primeiro ano, conhecido como linha Beauty'n Blue. Com a ajuda de uma equipe de profissionais do ramo de cosméticos, desenvolveram uma linha de maquiagens, a B.Touch para Beauty Factor, e uma série de fragrâncias combinadas com sabonetes e desodorantes - denominadas Beauty'n Man, Beauty'n Woman, e B.Kids.

A estratégia da empresa mudou em 2009, quando os produtos deixaram de ser vendidos somente por distribuidoras em salões e passaram a ser comercializados em lojas próprias, modelo franquia. A empresa, rapidamente, ganhou uma segunda fábrica, no interior de Santa Catarina, para 
comportar a demanda crescente. Em 2012, a Beauty Factor conquistou apelo internacional, ao ganhar visibilidade depois do uso de seus produtos por atores jovens de um seriado americano em redes sociais. Rapidamente a marca consagrou-se também no mercado estrangeiro. Além disso, no mesmo ano, a empresa começou a investir em produtos específicos para os públicos masculino e infantil.

Em 2017, a Beauty Factor contava com quatro fábricas e mais de 300 lojas físicas no Brasil, além de 22 lojas no exterior, localizadas nos Estados Unidos, Uruguai, Argentina, França, Itália, Portugal e Espanha. A empresa possui mais de quatro mil colaboradores em seus empreendimentos, com um modelo de negócios dinâmico, sempre atenta aos movimentos do mercado e atuando de forma ativa nas redes sociais e na mídia. A "pequena empresa" de Benedita Souza é hoje uma das principais empresas de cosméticos do país. 


\section{UMA ANÁLISE DO SEGMENTO HOMOSSEXUAL}

No dia seguinte, uma quarta-feira, Cristina levantou antes das seis da manhã e tomou seu café bem forte. Tinha dormido tarde, trabalhando na compilação dos dados a serem apresentados para a Beauty Factor, e queria alinhar os últimos pontos de seu projeto. Ela estava animada, pois acreditava na força do que iria defender aos executivos da firma, mas ao mesmo tempo um pouco insegura da receptividade quanto ao tema. Depois de mais algumas horas trabalhando na apresentação, partiu rumo à companhia.

A sala de reuniões da sede da Beauty Factor estava lotada. Além da equipe de marketing, estavam outros executivos e coordenadores interessados em ouvir o que Cristina tinha a dizer. Maria Fernanda parecia nervosa, receosa da receptividade dos demais membros da empresa e, ao mesmo tempo, esperançosa, acreditando que a consultora pudesse expor o cenário de forma mais clara.

Cristina iniciou sua fala pontualmente às 14 horas, com um sorriso no rosto e sua habitual elegância. Após cumprimentar cada um dos presentes, ela abriu a reunião:

- Boa tarde a todos. É sempre bom trabalhar com a Beauty Factor, pois minha relação com a empresa é longa e significativa. Hoje vim até aqui com a missão de apresentar um panorama sobre um segmento que está em alta no mercado e que, segundo minhas discussões com a Maria Fernanda, está nos planos da empresa, sempre moderna e conectada com as tendências.

Os executivos a reverenciaram e pareciam animados e curiosos. Ela, então, continuou:

- A Beauty Factor já está no mercado de cosméticos há 16 anos e atingiu certa maturidade. Embora as vendas estejam em crescimento constante, é preciso evitar a estagnação e chegou a hora da empresa acompanhar o que ocorre no mundo, ampliando sua área de interesse e focando-se em novos alvos. Sabemos que o país está em crise e diversificar é a palavra-chave neste momento. Com nosso novo projeto, estamos abrindo as portas da empresa para a diversidade. 
Foi possível ouvir cochichos e murmúrios baixos na sala, mas Cristina não se deixou abalar:

- O público que a Beauty Factor quer atender com maior atenção é o homossexual. Estamos falando de uma força de mercado, uma fatia de nossos clientes que pode não se sentir representada em nossas propagandas e anúncios na mídia. O Dia dos Namorados apresenta uma oportunidade de abordar esse novo segmento, mas antes de nos aprofundarmos nos planos que tenho para a empresa, gostaria de apresentar alguns dados.

Cristina andou pela sala de um lado para o outro e começou a apresentar alguns dos dados que havia reunido nas semanas anteriores:

- Bem, primeiramente, alguns dados gerais sobre o tema no Brasil. Em 2011, o Supremo Tribunal Federal brasileiro aprovou a união estável de casais do mesmo sexo. O país, segundo dados do Censo de 2010, é o primeiro a contabilizar os residentes com cônjuges do mesmo sexo, tem mais de 60 mil casais homossexuais.

- Mas esse número deve ser muito maior hoje em dia, não é, Cristina? - ponderou Maria Fernanda.

- Certamente é maior. A Cognatis, uma empresa de consultoria paulistana, acredita que, como foi a primeira vez que o Censo abordou essa questão e como o preenchimento é opcional, é de esperar que existam muito mais casais homossexuais do que os que se autodeclararam. Ah! $\mathrm{E}$ vale lembrar que essa mesma consultoria verificou, com base nos dados do Censo 2010, que a renda mensal média familiar dos casais de mesmo sexo é quase o dobro de uma família formada por casal heterossexual! É ou não é um bom mercado? E se a gente considerar o mercado mundial levando em consideração lésbicas, gays, bissexuais e transgêneros alcançamos o valor de 743 bilhões de dólares. Valores esses encontrados em pesquisas internacionais de renome como o Journal of Consumer Reasearch, pessoal! Além disso, com uma renda familiar alta, e frequentemente sem dependentes, os consumidores homossexuais gastam mais com festas, viagens, novidades tecnológicas e, principalmente, vestuário/moda.

Cristina destacou as seguintes informações sobre o mercado consumidor brasileiro (vide Figura 1). 


\section{ANA PAULA KIELING}

Figura 1 Mercado Consumidor Homossexual Brasileiro

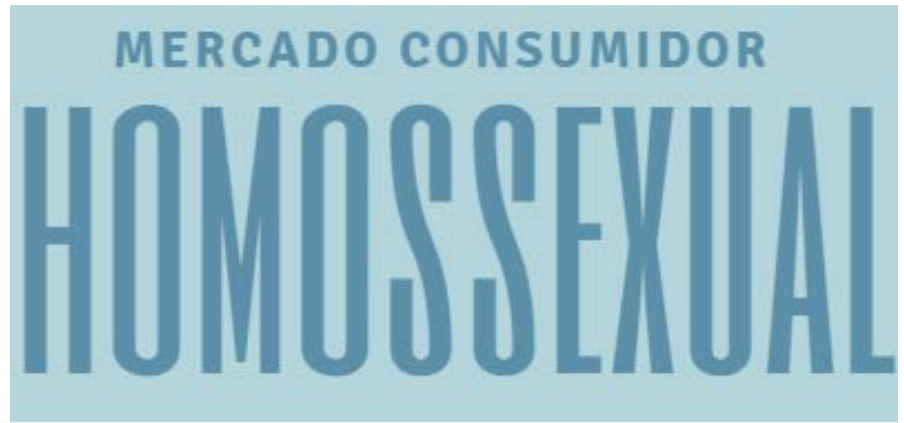

18 MILHÕES DE BRASILEIROS

$36 \%$ CLASSE A

$47 \%$ CLASSE B

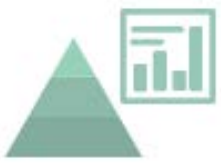

150 Bilhões Por ano

\section{BILHÕES - POTENCIAL DE EXPANSÃO DO SEGMENTO}

Informaçōes: www.mundodomarketing.com.br

Fonte: Elaborado pelos autores (2018).

- Muito interessante. Realmente é um público com alto poder aquisitivo, pena que ainda há muito preconceito a respeito. Tenho vários amigos que acham que mostrar relacionamentos homossexuais na mídia pode incentivar a homossexualidade - comentou João Augusto, um dos executivos da Beauty Factor.

- Falando nisso, a agência publicitária Meio e Mensagem publicou uma pesquisa realizada por sua equipe abordando o comportamento dos consumidores brasileiros em relação aos anúncios com personagens homossexuais. Eles identificaram que cerca de $80 \%$ dos brasileiros afirmam não se importar se os protagonistas de anúncios são homossexuais ou hete- 
rossexuais, e $68 \%$ dizem que a presença de homossexuais não mudaria sua decisão de compra. Animador, não? Porém, quando questionados sobre a opinião dos outros com relação ao tema, mais da metade dos participantes respondeu que "os outros" não aprovariam e 36\% disseram que televisão não é lugar para casais homossexuais, o que revela certo preconceito velado - destacou Cristina.

Nesse momento, a consultora mostrou mais alguns dados do Instituto Datafolha que apontam uma ligeira mudança nas opiniões dos brasileiros sobre o tema, conforme apresentado na Figura 2.

Figura 2 Inclinação Ideológica dos Brasileiros

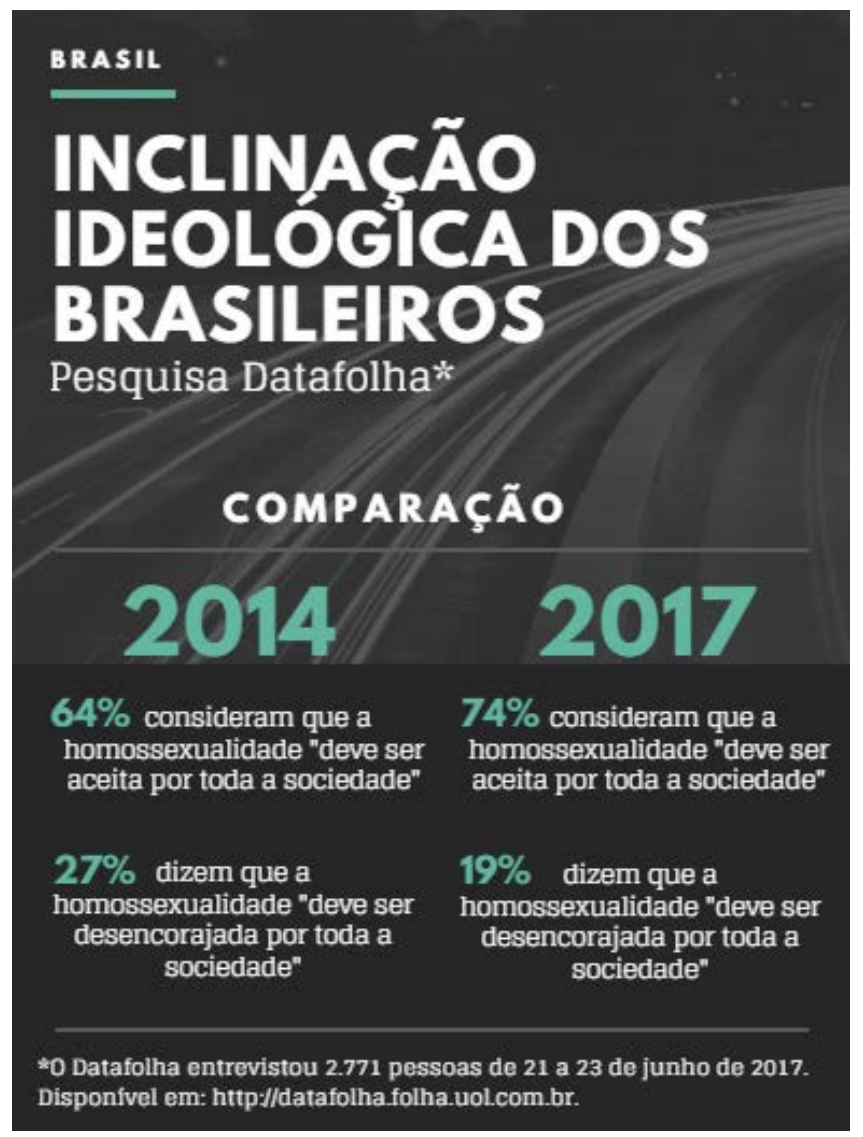

Fonte: Elaborado pelos autores (2018). 
Um dos executivos presentes, Caio Bernardes, fez um comentário "engraçadinho" e os demais começaram a conversar entre si. Maria Fernanda pediu atenção aos colegas e Cristina prosseguiu.

- Outra informação importante que gostaria de repassar vem do Gay Press Report de 2014, que se trata de um relatório anual publicado nos Estados Unidos há mais de 20 anos, e que rastreia toda a publicidade voltada ao público homossexual veiculada na imprensa americana. Segundo o relatório, os gastos nessa área, nos EUA, em 2014, foram estimados em mais de 400 milhões de dólares, enquanto que, em 1999, por exemplo, o total de investimentos era de 120 milhões de dólares. Seguindo essa tendência, a proporção de anúncios específicos continua crescendo e hoje é responsável por mais de $60 \%$ de todos os anúncios veiculados.

Maria Fernanda complementou a fala de Cristina:

- Sabemos que os Estados Unidos são um reflexo do que almejamos ser em termos de alcance de vendas. Além disso, o país sempre antecipa tendências no ramo de cosméticos. Esse dado é muito importante para entender o peso desse segmento, Cristina.

- Com certeza, Maria Fernanda. Na verdade, nem precisamos olhar para "fora de casa" para enxergar essa demanda e oportunidade. Nos últimos anos, o Brasil tem investido em anúncios com casais homossexuais ilustrando revistas e em posts de redes sociais de diversas empresas. Entretanto a impressão que dá é que muitas companhias não sabem ao certo qual a melhor forma de fazê-lo e mal sabem se o público geral será receptivo à representação dessa minoria. - respondeu Cristina, prontamente.

Na sequência, Luciano Lima, um dos executivos presentes, manifestou-se:

- Interessante, mas não lembro de nenhuma propaganda desse tipo. Poderia exemplificar, Cristina?

- Claro, Luciano. Um exemplo é o caso da marca de pasta de dentes "Close Up", que desenvolveu uma ação publicitária no Dia do Beijo, do ano passado, chamada "Liberte seu Beijo", que contou com casais homossexuais se beijando e a frase "Não julgue, beije", em destaque, pintada no rosto dos amantes. A Unilever, detentora da marca, apresentou seis diferentes 
figuras representando a diversidade de beijos e seus casais - abordando os temas de raça, idade e gênero. Inclusive, essa propaganda fez tanto sucesso que voltou ao ar recentemente - pelo menos no Instagram, pois ainda hoje apareceu uma postagem patrocinada no meu feed. E no canal do YouTube da marca é possível ver a campanha completa.

- Verdade, Cristina! Ainda essa semana li algo sobre isso na internet, pois no início gerou bastante polêmica, não é? - disse Maria Fernanda.

- Exato. Falarei mais sobre esse aspecto depois. Outro caso bastante conhecido é o da marca "O Boticário". A empresa introduziu um casal homossexual na campanha de Dia dos Namorados do ano passado, entre outros casais, e gerou muita repercussão. A companhia ganhou até prêmio por essa ação, sabiam? - comentou Cristina.

- Que prêmio, Cristina? - perguntou Caio, curioso.

- O Effie Wards Brasil 2015. Ganharam o prêmio máximo da noite, por sinal. A ação se chamava "Um Dia dos Namorados para todas as formas de amor" e mostrava casais de diferentes orientações sexuais trocando presentes da marca no Dia dos Namorados.

- Esse vídeo é incrível, emociona. Não é por acaso que gerou tanto burburinho nas redes. Na minha opinião, precisamos de algo com esse impacto. - disse Maria Fernanda.

- De fato, o vídeo é único e, por isso, gerou muitas opiniões divergentes, Andrea. Quero comentar esse caso com mais detalhamento a seguir, pois, embora as perspectivas de trabalho a partir da segmentação em diversidade sejam animadoras, elas também podem gerar efeitos colaterais e a empresa deve estar pronta para isso. 


\section{DESAFIOS PELO CAMINHO}

Após apresentar um panorama das campanhas que privilegiam o público homossexual, Cristina decide mostrar quais são os principais desafios enfrentados pela comunidade e seus reflexos no mercado publicitário e nas empresas. Ela segue sua apresentação comentando:

- Embora o mercado esteja aberto para o segmento, nem tudo são flores. Infelizmente, ainda há muita violência e preconceito relacionados à comunidade homossexual no Brasil e no mundo. Um relatório do Grupo Gay da Bahia informou que ocorreram 318 homicídios de LGBTs no Brasil em 2015. Em 2016, esse número foi para 343 e até o mês de agosto de 2017 já eram cerca de 250 mortes. Um gráfico crescente e que resulta em uma expectativa de vida para os homossexuais de 35 anos, o que é menos da metade da média nacional. São Paulo é o estado que lidera o ranking dos mais violentos, com 55 assassinatos a homossexuais, chamados de crimes de ódio - informou Cristina. As informações geraram burburinhos que tiveram de ser contidos por Maria Fernanda, para que Cristina prosseguisse.

- Além disso, busquei dados científicos sobre o tema em pesquisas nacionais e internacionais de grandes universidades. Vários estudos apontaram que os homens são mais preconceituosos e, inclusive, eles reagem mais negativamente aos anúncios com conteúdo homossexual, se comparados às mulheres. Outro dado interessante é com relação à religião: quanto mais religioso, pior será a reação do consumidor diante do anúncio.

Após uma breve pausa, Cristina continuou com sua apresentação. Nesse momento, ela recebia atenção total de todos os executivos:

- Quando voltamos nossos olhos para o mercado homossexual, os dados confirmam que eles tendem a comprar de marcas que anunciam diretamente para o segmento. Marcas como "Calvin Klein", "Benetton" e "Banana Republic" já entenderam isso e anunciam com frequência para eles. Essas marcas sabem que esse público costuma gastar até 30\% mais em bens de consumo do que os heterossexuais. Como a maioria pertence às classes A e B e não possui filhos, consome mais carros, viagens, imóveis. Um grande potencial de mercado! 
O som de um celular interrompe a fala de Cristina. Após pedir desculpas, o dono desliga o aparelho e pede que ela fale sobre os anúncios publicitários homossexuais no Brasil.

- Bom, já ia chegar nesse ponto. Os dados indicam que os anúncios brasileiros retratam a homossexualidade por meio do humor por acreditarem que, dessa forma, o grupo heterossexual não se sente tão "ofendido". No entanto a temática no país ainda é conduzida de forma lenta e preconceituosa.

Uma das analistas de marketing da Beauty Factor, Andrea Andrade, reforçou os dados, comentando sobre a veiculação de campanhas publicitárias:

- Na semana passada, ainda, falamos sobre isso no MBA, que antigamente até haviam campanhas publicitárias relacionadas a homossexuais nos EUA, no início dos anos de 1980, mas elas cessaram por conta do aumento nos números da AIDS, que era preconceituosamente vinculada aos gays. Somente anos depois, quando as pessoas entenderam melhor a doença, esse público voltou aos anúncios.

- É chocante, mas verdadeiro, Andrea. - disse Cristina, enquanto bebia um gole de água antes de seguir com sua apresentação.

- Continuando, vamos voltar à prática de marketing nos dias de hoje: a ação da "Close Up" e suas consequências. A Unilever sofreu represálias e ameaças de boicote de uma parte do público, enquanto outra parte recebeu bem a proposta e elogiou o posicionamento da empresa. As redes sociais da marca foram infestadas com comentários homofóbicos e preconceituosos. Não foi a primeira vez que a marca investiu nesse tipo de estímulo - um ano antes, em 2015, divulgou uma campanha similar no Instagram e, ao ser criticada, foi firme em seu posicionamento e afirmou que nunca iria deletar a fotografia de sua conta, independente do teor dos comentários.

Os participantes da reunião pareciam interessados e ouviam atentos. Ela complementou:

- No caso da marca "O Boticário", a discussão saiu das redes e foi levada para o Conselho Nacional de Autorregulamentação Publicitária (Conar) com o pedido de retirada do ar da campanha. Centenas de reclamações 


\section{ANA PAULA KIELING}

foram enviadas ao órgão (mais de 500 para ser exata) por consumidores que se sentiram ofendidos e consideraram o anúncio desrespeitoso à sociedade e à família. Por sua vez, outras 500 mensagens foram enviadas em apoio à empresa, que defendeu até o fim a sua posição e pronunciou-se dizendo que sua proposta busca, com respeito e sensibilidade, abordar as mais diferentes formas de amor. O fim da história, resumidamente, foi a absolvição da empresa.

- Com licença, Cristina! Desculpe interrompê-la, mas como venho acompanhando este caso, acho importante dizer que o relator do processo justificou a sentença dizendo que o comercial mostrou apenas aspectos da realidade contemporânea. Então, percebam que não podemos mais fechar os olhos para essa nova realidade - enfatizou Maria Fernanda. 


\section{SEGMENTAR É PRECISO! MAS COMO?}

Já passava das 18 horas quando a consultora apresentou seus argumentos finais na reunião com a Beauty Factor. Após dispor de prós e contras quanto a investimentos no segmento, Cristina afirmou:

- O primeiro passo foi dado. Meu intuito nesse primeiro encontro é trazer para vocês o contexto sobre o segmento e o mercado. Como vocês notaram, não é tão simples quanto parece. Estratégias com foco em públicos-alvo tão sensíveis a preconceitos quanto esse exigem cuidado e um alto grau de delicadeza para serem bem-sucedidas. Entretanto acredito que a Beauty Factor tem tudo para conquistar de vez esse mercado, fazendo com que mais pessoas, com diferentes interesses, apaixonem-se pela marca.

Maria Fernanda sorri e complementa:

- Cristina, nosso encontro foi muito esclarecedor. Sem dúvida é algo para trabalharmos juntos - e rápido! Nosso prazo é curto, pois queremos lançar a campanha até dia 12 de maio, um mês antes do Dia dos Namorados. A verba já foi designada no planejamento anual, entretanto, quero conversar com meus colegas, pois preciso da aprovação de todos para começarmos a trabalhar nas estratégias.

- Sem problemas. Ligue-me até o fim da semana com novidades, aguardarei.

Naquela semana, Cristina atendeu a outros clientes e, na sexta-feira, recebeu uma ligação de Maria Fernanda:

- Cristina, conversei com meus colegas e, mesmo frente a resistência de alguns, a maioria é a favor do investimento na campanha com foco no público homossexual. Vamos em frente, quero agendar outra reunião para segunda-feira, assim, você apresenta a segunda parte da proposta, no caso, as estratégias a serem desenvolvidas e executadas.

- Que ótima notícia. Vou terminar de preparar a proposta da Beauty Factor hoje mesmo e encontramo-nos novamente na segunda-feira. Pode ser às 14 horas?

- Perfeito. Só um adendo: lembre-se que o nosso objetivo é atingir um novo público, mas de forma alguma queremos ferir as expectativas do 


\section{ANA PAULA KIELING}

público que conquistamos até agora. Sabemos que muitos de nossos clientes podem sentir-se desconfortáveis com essa posição da marca. Estou ansiosa para ver o que você preparou para nós. Um abraço e até breve! - disse Maria Fernanda.

- Com certeza, considerarei essa variável. Vemo-nos na próxima semana. Abraços!

Prontamente, Cristina abriu as planilhas em seu computador e continuou o desenvolvimento da proposta de segmentação da campanha de Dia dos Namorados da Beauty Factor, que estava em stand by desde o último encontro. Na verdade, ela acreditava que a empresa não iria em frente com a ideia devido aos comentários e à postura que identificou em alguns participantes da primeira reunião. "Que bom", pensou consigo mesma.

Animada, repetiu a leitura de todo material que havia coletado previamente e retomou os estudos sobre o tema e o que já existe relacionado ao segmento no mercado, com o objetivo de planejar uma ação inovadora, diferente e apaixonante. Em sua cabeça, muitas questões precisavam ser respondidas com aquela proposta: "Qual abordagem utilizar? Que estratégias terão melhor aceitação? Como a empresa pode se beneficiar com cada estratégia?". E seu dilema principal: "Qual a melhor forma de anunciar o produto para o segmento homossexual sem desrespeitar os interesses dos segmentos atendidos pela empresa até o momento?”. Mãos à obra, Cristina! 


\section{NOTAS DE ENSINO}

\section{OBJETIVOS EDUCACIONAIS DO CASO}

O caso, que retrata o interesse de uma empresa de cosméticos em se inserir no mercado-alvo homossexual e procura informações sobre como anunciar para esse público, tem por objetivo oferecer aos alunos vivência nas situações relacionadas à tomada de decisão e estratégia no âmbito da segmentação de mercado. A proposta é fazer com que os estudantes se coloquem na posição de gestores de marketing da empresa para interpretar o dilema e, a partir disso, apresentar estratégias possíveis para que a segmentação voltada ao público homossexual obtenha êxito.

\section{UTILIZAÇÃO RECOMENDADA}

Este caso foi desenvolvido para aplicação em cursos de graduação e pósgraduação em Administração de Empresas, Marketing e Publicidade e Propaganda. O debate inclui temas como segmentação de mercado, estratégia de marketing, como também publicidade e propaganda, a serem abordados nas disciplinas de Administração Mercadológica, Gestão de Marketing, Estratégias de Comunicação em Marketing e Segmentação de Mercado.

\section{FONTES DE DADOS}

A construção do caso foi baseada em dados secundários obtidos a partir de dados de pesquisas nacionais e internacionais publicadas em periódicos científicos, reportagens na internet sobre a temática de anúncios publicitários segmentados para o público homossexual, bem como dados da teoria que suportassem as notas de ensino. A narrativa que foi desenvolvida para estruturar o caso é fictícia, bem como a empresa e os personagens citados no trabalho. Por se tratar de uma temática polêmica, o caso foi aplicado em sala de aula previamente à sua publicação, assim, permitindo ajustes em seu conteúdo que visam apoiar o professor. 


\section{ANA PAULA KIELING}

\section{RELEVÂNCIA DO CASO}

Identificar as situações vivenciadas por gestores de empresas é essencial para formação de profissionais na área de Administração e Marketing, considerando os desafios enfrentados pelas empresas neste segmento. $\mathrm{O}$ contexto de segmentação de mercado vem sendo ampliado ao longo do tempo e, cada vez mais, as empresas interessam-se por suprir necessidades e desejos de grupos de interesse específicos, como a comunidade homossexual, objeto de estudo deste caso. Habilitar estudantes da área à solução de problemas relacionados ao mercado e à segmentação com foco em minorias permite o desenvolvimento de estratégias de marketing e amplia a discussão acerca do impacto social de anúncios publicitários direcionados a um público específico com potencial consumidor. Além disso, o caso é relevante para o debate sobre inclusão de minorias e redução do preconceito existente quanto ao público homossexual e suas implicações na sociedade.

\section{TÓPICOS PEDAGÓGICOS}

O caso em questão pode ser adaptado aos objetivos do professor, à modalidade de ensino e ao tamanho da turma, porém sugere-se como organização da aplicação a seguinte estrutura:

a. Leitura e análise individual realizada pelos alunos antes da aula.

b. Divisão da turma em equipes de até três pessoas, para análise e discussão do caso e das questões propostas (tempo sugerido: 1h30min)

c. Apresentação e discussão das análises elaboradas pelos grupos em painéis, estimulando a colaboração entre as equipes (tempo sugerido: 1 hora).

De forma a estimular o debate em sala de aula, sugere-se a exibição de anúncios publicitários de marcas que abordaram o tema da homossexualidade. Enumerando exemplos de campanhas já veiculadas na mídia, é possível citar: "Campanha de Dia dos Namorados O Boticário" (O BOTI- 
CÁRIO, 2018); Campanha "Close Up Não julgue, beije” (CLOSE UP, 2018); e Campanha "Gol Dia das Mães: Gilberto e Rodrigo" (GOL, 2018).

Como complemento, estimula-se o professor para a apresentação de dados atualizados sobre o segmento abordado, bem como solicitar pesquisa prévia aos alunos acerca do tema, inclusive, sobre campanhas de comunicação de marketing voltadas para o público homossexual.

\section{CONSIDERAÇÕES}

O tema abordado no caso é polêmico e exige habilidade do professor para conduzir a discussão de forma a evitar conflitos. Entende-se que este trabalho pode apresentar tanto implicações práticas para a área de marketing, por meio da discussão do dilema referente ao direcionamento ao segmento homossexual em anúncios publicitários, quanto implicações sociais, à medida que instiga o debate sobre a aceitação da diversidade e a inclusão de minorias no mercado consumidor. É importante o professor destacar o papel assumido pelos alunos, diante do caso, como gestores de marketing, buscando solucionar o dilema da empresa de forma mais profissional possível.

\section{QUESTÕES PARA DISCUSSÃO}

As questões foram desenvolvidas de modo a estimular a reflexão dos alunos, com intuito de gerar conhecimento que possa ser aplicado na esfera empresarial de forma realística. Os questionamentos foram estruturados para que o aluno, primeiramente, identifique todas as variáveis que possam influenciar o comportamento do consumidor e a tomada de decisão. Em seguida, é desafiado a refletir sobre as teorias de segmentação de mercado, para, enfim, identificar as características de cada público. A última questão discute o desenvolvimento de estratégias de divulgação de marketing para ambos os públicos: heterossexual e homossexual. Dessa forma, o aluno estará habilitado a aplicar os conhecimentos adquiridos em sala considerando os obstáculos diários enfrentados pelas organizações no campo mercadológico. Para tal, são sugeridas as seguintes questões: 
1 - Diversos fatores afetam o comportamento dos consumidores em suas escolhas de consumo, sendo essa uma preocupação das empresas. Quais características influenciam o consumidor no processo de decisão de compra? No caso da Beauty Factor, quais variáveis você considera que devem ser observadas para a segmentação com foco no público homossexual?

O Modelo do Processo de Decisão do Consumidor - PDC (BLACKWELL; MINIARD; ENGEL, 2005) utiliza três conjuntos de variáveis que podem influenciar as atitudes dos consumidores: diferenças individuais, influências ambientais e processos psicológicos.

As diferenças individuais dizem respeito às questões referentes à demografia, à psicografia, aos valores e personalidade, ao conhecimento e atitudes, entre outros fatores. A variável demografia explica as mudanças na constituição da população, como as pessoas alocam seus recursos financeiros, gastam seu tempo, definem suas amizades, etc (BLACKWEEL; MINIARD; ENGEL, 2005, p.195). Além disso, fornece informações sobre as questões econômicas, políticas e sociais, como o corte de impostos e como a população gastará esse recurso extra, por exemplo. Outra aplicação é na demanda industrial, podendo revelar produtos ou serviços industriais necessários a empresas em crescimento no mercado.

A demografia econômica, que estuda as características econômicas da população, também é destacada por Blackwell, Miniard e Engel (2005). Ela é composta por um grande conjunto de variáveis, dentre as quais, pode-se destacar: idade, gênero, renda, religião, estado civil e orientação sexual, por exemplo. Em pesquisas de marketing, a demografia é utilizada de duas formas: como descrição de segmentos de mercado e em análise de tendências.

As influências ambientais, por sua vez, referem-se à cultura, classe social, influência da família e outros. Para Blackwell, Miniard e Engel (2005), a cultura está ligada à ideia de valores e outros símbolos que auxiliam os indivíduos na interpretação, comunicação e avaliação na sociedade. Quando se fala em classe social, refere-se, de fato, ao conjunto de pessoas que compartilham valores, interesses e comportamentos semelhantes, sendo 
que as diferenças do status econômico podem levar a diferentes formas de comportamento de consumo. A cultura é influenciada, ainda, por fatores como etnia, raça, religião e identidade nacional ou regional. Ao tratar de influência pessoal, os autores destacam que é a família que exerce grande poder de influência, pois é a unidade de decisão primária na vida do indivíduo (BLACKWEEL; MINIARD; ENGEL, 2005).

Ademais, os processos psicológicos relacionam-se ao processamento de informação, aprendizagem, mudança de comportamento e de atitude. Essas variáveis, segundo os autores, determinam as percepções no tocante à marca, ao produto e às decisões de compra. O processamento da informação é a forma como o consumidor transforma, reduz, elabora, armazena, redescobre e recupera as informações recebidas pelos anunciantes (BLACKWELL; MINIARD; ENGEL, 2005). A aprendizagem é o processo pelo qual a experiência leva a mudanças em conhecimento e comportamento. Por fim, as mudanças de comportamento e atitude são objetivos centrais do marketing e refletem as influências psicológicas básicas dos indivíduos. Como se sabe, cada consumidor tem níveis de necessidades de cognição diferentes que vão determinar o processo de tomada de decisão de compra (MOWEN; MINOR, 2003, p.152).

Ao contratar os serviços da consultora Cristina Albuquerque, por considerar a segmentação voltada para o público homossexual, a Beauty Factor atenta para as diferenças individuais a partir da descrição de segmentos de mercado, em que se combinam perfis demográficos de um segmento com seus comportamentos de consumo.

\section{2 - Segmentar tem-se tornado um processo vital para os profissionais de marketing. Baseado nisso, conceitue a segmentação de mercado, des- creva sua importância para o desenvolvimento de estratégias de comu- nicação de marketing e aponte de que forma a Beauty Factor pode se beneficiar ao abordar o novo segmento.}

Nem sempre é possível as empresas explorarem um mercado-alvo inteiro e, além disso, cada vez mais, observa-se um mercado extremamen- 
te heterogêneo. Por isso, é fundamental que, antes de estabelecer um plano de comunicação de marketing, seja realizada a análise de segmentação de mercado.

Segundo Ogden e Crescitelli (2007), o objetivo da segmentação de mercado é observar o comportamento do consumidor. Os autores afirmam que cada grupo de consumidores com respostas semelhantes é classificado em um subgrupo ou segmento de mercado. Para Churchill Jr. e Peter (2012), a segmentação de mercado é um processo que consiste em dividir o mercado em grupos de compradores com necessidades, desejos, valores e comportamentos de compra similares.

A segmentação de mercado é importante por identificar e traçar o perfil dos grupos distintos de consumidores, uma vez que nenhuma empresa pode vencer se seus produtos se assemelham a qualquer outro no mercado. Como parte do processo de gestão estratégica de marca, cada oferta deve representar os tipos certos de associação na mente dos consumidores no mercado-alvo (KOTLER; KELLER, 2012). De acordo com Kondo et al. (2009, p.131), o planejamento estratégico de marketing deve responder a três questões principais: "i) Qual é o negócio em que estamos agora? ii) O que está acontecendo no ambiente? iii) O que o negócio deveria estar fazendo?”.

A partir da segmentação é possível a criação de uma posição ou imagem na mente do consumidor que seja diferenciada em relação aos produtos oferecidos pela concorrência. Segundo Kotler e Keller (2006, p.305), o posicionamento de mercado é "a ação de projetar o produto e a imagem da empresa para ocupar um lugar diferenciado na mente do público-alvo”. Envolve as seguintes atividades: a identificação dos conceitos de posicionamento possíveis para cada mercado-alvo e seleção, desenvolvimento e comunicação dos conceitos de posicionamento escolhidos. De fato, entender as diferenças é particularmente importante considerando a diversidade cultural existente, os mercados altamente competitivos e a preocupação das corporações com a responsabilidade social de tratar todos os públicos com respeito (BHAT; LEIGHT; WARDLOW, 1998).

A Beauty Factor já trabalha há algum tempo com segmentação quanto à idade (públicos adulto e infantil) e gênero (masculino e feminino). De- 
senvolver estratégias de segmentação com o foco para uma fatia específica de mercado, como a comunidade homossexual, permite a ampliação do público-alvo da empresa, gera inclusão de minorias e apoio à diversidade temáticas altamente relevantes na sociedade moderna, além de tornar seus esforços de marketing mais direcionados e concisos.

Anúncios com casais homossexuais começaram a despontar na mídia com mais frequência nos últimos anos e a reação do público tem gerado grande repercussão (OLIVEIRA, 2015). Além disso, acredita-se que a comunidade de Lésbicas, Gays, Bissexuais, Travestis, Transexuais e Transgêneros (LGBTs) considera sua inclusão no mercado-alvo como um reconhecimento do progresso do movimento social homossexual (PEÑALOZA, 1996)

Burnett (2000) define o público homossexual como sendo uma mina de ouro descoberta de alto poder aquisitivo. $\mathrm{O}$ autor explica que as empresas dedicadas à segmentação de gays e lésbicas têm percebido isso e vêm expandindo o seu mercado para além de clubes e livrarias e incluindo novos serviços, tais como companhias de viagens, assessoria jurídica, médica, financeira e serviços de comunicação.

3 - Levando em consideração as informações dispostas no caso da Beauty Factor, crie um perfil das características de consumo do público homossexual, assim como dos obstáculos gerados ao se tentar atingir esse mercado.

A Beauty Factor é uma empresa moderna e, por esse motivo, quer inovar em suas ações de marketing por meio da aproximação com um público específico, que celebra a diversidade, direcionando seus esforços da campanha de Dia dos Namorados 2017 para o segmento homossexual. No Quadro 1, estão listadas algumas características desse público, de modo a apoiar o desenvolvimento de uma proposta de segmentação. 


\section{ANA PAULA KIELING}

Quadro 1 Características relacionadas ao consumo homossexual

\section{Características RELACIONADAS AO CONSUMO HOMOSSEXUAL}

1. Público com alto poder aquisitivo. Estão inseridos principalmente nas classes A e B (BAGGIO, 2009).

2. Mercado composto por lésbicas, gays, bissexuais e transgêneros, representam um mercado mundial de 743 bilhões de dólares (BAGNALL, 2011).

3. Renda mensal familiar dos casais de mesmo sexo é de $\mathrm{R} \$ 5.208$, quase o dobro de uma família formada por casal heterossexual (EXAME, 2014).

4. Costumam gastar até $30 \%$ a mais em bens de consumo do que o público heterossexual (BAGGIO, 2009).

5. Estrutura familiar, na grande maioria, sem filhos e por isso consomem mais carros, viagens e imóveis (SOUSA, 2012).

6. Em média, gastam $50 \%$ a mais em pacotes turísticos se comparados aos heterossexuais (EXAME, 2014).

7. O público LGBTQ costuma ler revistas de grande circulação e não somente publicações dedicadas a seu segmento (OAKENFULL; GREENLEE, 2005).

8. Na TV, costumam assistir a comédias e dramas, além de programas jornalísticos e de ficção científica (BURNETT, 2000).

Fonte: Elaborado pelos autores.

Além disso, é importante listar os obstáculos presentes ao realizar uma segmentação com foco em minorias e/ou na diversidade, como no caso do público homossexual (vide Quadro 2). 
Quadro 2 Desafios da Segmentação focada no público homossexual

\section{Desafios da Segmentação Focada no Público Homossexual}

1. O grande público acredita que a televisão não é "lugar" de homossexuais (MEIO E MENSAGEM, 2014).

2. Muitas pessoas não assumem seu próprio preconceito (MEIO E MENSAGEM, 2014).

3. No geral, homens heterossexuais têm atitudes mais negativas contra homossexuais do que mulheres (UM, 2014).

4. Indivíduos com alto grau de religiosidade têm atitudes mais negativas em relação aos homossexuais se comparados àqueles que possuem um grau mais baixo (DOEBLER, 2015).

Fonte: Elaborado pelos autores.

Ao estabelecer estratégias de comunicação de marketing para abarcar um novo mercado é imprescindível conhecer bem esse público, suas características, preferências, hábitos de consumo e estilo de vida. No entanto, quando se trata de um público como o homossexual, é necessário, também, verificar e levantar os pontos negativos que essa abordagem pode gerar para o restante do público, pois as opiniões divergem sobre o tema. Ao tratar o público homossexual, questões religiosas (DOEBLER, 2015) e a própria cultura da sociedade influenciam diretamente os demais, principalmente, quando consideramos o preconceito masculino à homossexualidade. Muitos homens consideram a heterossexualidade importante para a sua masculinidade e, por isso, rejeitam homens que violam a norma heterossexual (UM, 2014). Essa crença certamente é um desafio para os profissionais de marketing e uma barreira a ser ultrapassada.

4 - Baseado nas informações obtidas anteriormente, apresente estratégias que possam ser desenvolvidas para disseminar a campanha da empresa de cosméticos Beauty Factor com foco no segmento homossexual, especificando o meio a ser utilizado e o público-alvo a ser atingido. 
Oakenfull, McCarthy e Greenlee (2008) apresentam três soluções para a abordagem homossexual por anunciantes. A primeira refere-se ao investimento em periódicos dedicados exclusivamente ao público homossexual; a segunda é investir na grande mídia e correr o risco da não aceitação por parte dos consumidores heterossexuais; e a terceira é a utilização de simbolismos da subcultura homossexual na grande mídia, para, assim, atingir o público de forma sutil e não tão "agressiva".

Ademais, deve-se considerar o marketing de relacionamento como uma estratégia para monitorar o feedback dos clientes no que tange a essa nova postura da organização. Essa estratégia "transforma essa informação sobre mercado e concorrência em uma nova informação sobre o produto" (KIELING et al., 2017, p.181). Como o objetivo da campanha é destacar a beleza da diversidade e que a Beauty Factor tem o produto certo para agradar a todos os amantes neste Dia dos Namorados, a campanha será direcionada de duas formas diferentes.

Assim, considerando que o público feminino se mostra mais receptivo aos anúncios com conteúdo homossexual (UM, 2014), além de ser uma parcela essencial do público-alvo da empresa Beauty Factor, parte das estratégias de comunicação será voltada especialmente para elas. Dessa forma, propõe-se a veiculação de anúncios em revistas femininas, bem como nas redes sociais - Google Ads, Facebook e Instagram. Por meio do uso de filtros, o investimento de mídia será direcionado para o público feminino, embora enfatize a comunidade homossexual em seu conteúdo. Além disso, para o público em geral, os investimentos serão direcionados para a mídia de massa, televisão e redes sociais. Optou-se por tratar do tema por meio de símbolos da cultura homossexual, nesse caso, o arco-íris, e não por meio de personagens, ou seja, de forma implícita (vide Quadro 3). 
Quadro 3 Estratégias de Comunicação de Marketing para anúncio homoafetivo

\begin{tabular}{|c|c|c|}
\hline Mídias & $\begin{array}{l}\text { Público Feminino e } \\
\text { Homossexual }\end{array}$ & Público em Geral \\
\hline $\begin{array}{l}\text { Facebook, } \\
\text { Instagram e } \\
\text { Google Ads }\end{array}$ & $\begin{array}{l}\text { Campanha de abrangência nacio- } \\
\text { nal por meio da criação de anún- } \\
\text { cios publicitários com persona- } \\
\text { gens homossexuais (casais gays e } \\
\text { lésbicos) em cenas de afeto. As ce- } \\
\text { nas ocorrerão em diferentes pai- } \\
\text { sagens do Brasil, onde cada uma } \\
\text { destaca um produto da linha. As } \\
\text { frases envolvem amor, diversida- } \\
\text { de, beleza e cuidado para todos } \\
\text { os casais. As cores do arco-íris se- } \\
\text { rão utilizadas. Investimentos nas } \\
\text { redes sociais direcionados, por } \\
\text { meio de filtros. Serão seleciona- } \\
\text { dos os perfis femininos, além de } \\
\text { homossexuais, com idade de } 18 \text { a } \\
60 \text { anos. }\end{array}$ & $\begin{array}{l}\text { Campanha de abrangência } \\
\text { nacional. Criação de anún- } \\
\text { cios publicitários divulgan- } \\
\text { do a campanha da empresa } \\
\text { Beauty Factor com símbo- } \\
\text { los da cultura homossexual } \\
\text { (arco-íris) e frases destacan- } \\
\text { do a beleza da diversidade. } \\
\text { O anúncio segue a mesma } \\
\text { linha do anúncio dirigido } \\
\text { ao público feminino e ao } \\
\text { público homossexual, no } \\
\text { entanto as cenas com casais } \\
\text { homossexuais são substitu- } \\
\text { ídas por imagens de som- } \\
\text { bra de casais distantes nas } \\
\text { paisagens. }\end{array}$ \\
\hline Televisão & \multicolumn{2}{|c|}{$\begin{array}{l}\text { Campanha em rede nacional com anúncio publicitário de } 30 \\
\text { segundos. O anúncio destacará o amor e a diversidade por meio } \\
\text { de paisagens bonitas do Brasil. Em cada paisagem, cenas de ar- } \\
\text { co-íris e a sombra de diferentes casais ao fundo, incluindo gays, } \\
\text { porém de forma sutil. Cada cena trará um produto da linha da } \\
\text { Beauty Factor. A campanha terá duração de } 20 \text { dias, sendo que } \\
\text { as primeiras inserções serão, de } 30 \text { segundos, distribuídas ao } \\
\text { longo da programação das principais emissoras do país, inclu- } \\
\text { sive, em horários nobres. O planejamento de mídia prevê que } \\
\text { ao decorrer da campanha, nos últimos dias de veiculação, um } \\
\text { formato de } 15 \text { segundos do mesmo anúncio será exibido em } \\
\text { diferentes horários. }\end{array}$} \\
\hline
\end{tabular}




\section{ANA PAULA KIELING}

\begin{tabular}{|l|l|l|}
\hline Revistas & $\begin{array}{l}\text { Anúncios da campanha em revis- } \\
\text { tas femininas, bem como em re- } \\
\text { vistas com foco no segmento } \\
\text { homossexual. Os anúncios se- } \\
\text { guem a linha de divulgação rea- } \\
\text { lizada nas redes sociais com algu- } \\
\text { mas adaptações, sendo um pouco } \\
\text { mais ousado nas revistas dirigidas } \\
\text { ao homossexual. }\end{array}$ & Sem estratégia específica. \\
\hline Jornais & Sem estratégia específica. & $\begin{array}{l}\text { Anúncios em encartes de } \\
\text { jornais dos principais veí- } \\
\text { culos do país, nas edições } \\
\text { de domingo, durante todo } \\
\text { o mês de junho. O anúncio } \\
\text { segue a ideia da divulgação } \\
\text { feita na televisão. Trabalha- } \\
\text {-se com símbolos da cul- } \\
\text { tura homossexual sem dar } \\
\text { destaque aos casais. }\end{array}$ \\
\hline
\end{tabular}

Fonte: Elaborado pelos autores. 


\section{REFERÊNCIAS}

BAGGIO, A.T. A temática homossexual na publicidade de massa para público gay e não-gay: conflito entre representação e estereótipo. In: $32^{\circ}$ CONGRESSO BRASILEIRO DE CIÊNCIAS DA COMUNICAÇÃO, Curitiba, 2009. Anais... Curitiba: Intercom, 2009.

BAGNALL, A. Does this ad make me look gay? New York: Adage, 2011.

BHAT, S.; LEIGH, T.W.; WARDLOW, D. L. The Effect of Consumer Prejudices on Ad Processing: Heterossexual Consumers' Responses to Homossexual Imagery in Ads. Journal of Advertising, v. 27, n.4, p. 09 - 28, 1998.

BLACKWELL, R. D.; MINIARD, P.W.; ENGEL, J.F. Comportamento do Consumidor. São Paulo: Thomson Learning, 2005.

BURNETT, J. J. Gays: Feelings about Advertising and Media Used. Journal of Advertising Research, v.40, n.1/2, p.75-84, 2000.

CHURCHILL, G. A.; PETER, J. P. Marketing: criando valor para os clientes. 3. ed. São Paulo, SP: Saraiva, 2012.

CLOSE UP. Campanha Não Julgue, Beije. Youtube. 04 fev. 2018. Disponível em: <https: / / www.youtube.com/watch?v=Z-yNxLMt9W8>. Acesso em: 04 fev. 2018.

DATAFOLHA. Ideias afinadas com esquerda voltam a empatar com pensamento de direita. 2017. Disponível em: <http://datafolha.folha.uol.com.br/opiniaopublica/2017/07/ 1898056-ideias-afinadas-com-esquerda-voltam-a-empatar-com-pensamento-de-direita.shtml> Acesso em: 10 jan. 2018.

DOEBLER, S. Relationships between Religion and Two Forms of Homonegativity in Europe - A Multilevel Analysis of Effects of Believing, Belonging and Religious Practice. PlosOne. United States, v.10, n. 8, e0133538, 2015.

EXAME. Como aproveitar o potencial de consumo dos gays. 2014. Disponível em: <http:// exame.abril.com.br/pme/diferentes-mas-iguais/ > . Acesso em: 28 abr. 2017.

EXTRA. Close Up publica foto de beijo gay e divide opiniões na web. 2015. Disponível em: $<$ http:/ / extra.globo.com/noticias/ economia/ closeup-publica-foto-de-beijo-gay-divide-opinioes-na-web-17532556.html>. Acesso em: 28 abr. 2017.

GAY PRESS REPORT. 2014 Gay Press Report. Rivendall Media Co., Inc. Disponível em: <http:/ / rivendellmedia.com/documents/GayPressReport2014.pdf > Acesso em:15 jan. 2016.

GGB. Relatório 2015 - Assassinatos de LGBT no Brasil. Salvador, 2015. Disponível em: http:/ / pt.calameo.com/read/0046502188e8a65b8c3e2. Acesso em: 28 abr. 2017.

GGB. 2017. Brasil é o país que mais mata LGBTI: A comunidade pede paz! Salvador, 2017. Disponível em: <https:/ / grupogaydabahia.com.br/2017/08/18/brasil-e-o-pais-que-mais-mata-lgbti-a-comunidade-pede-paz/>. Acesso em: 05 jan. 2018. 


\section{ANA PAULA KIELING}

GOL. Campanha Dia das Mães - Gilberto e Rodrigo. Youtube. 2015. Disponível em: $<$ https: / / www.youtube.com/watch?v=Co6Oe-9PRqY>. Acesso em: 04 fev. 2018.

G1. Propaganda de O Boticário com casais gays vence prêmio publicitário, 2015. Disponível em: <http:/ / g1.globo.com/economia/midia-e-marketing/noticia/2015/10/propaganda-da-boticario-com-casais-gays-vence-premio-publicitario.html> Acesso em: 28 abr. 2017.

G1. Conar absolve Boticário por propaganda com casais gays, 2015. Disponível em: <http:/ / g1.globo.com/economia/midia-e-marketing/noticia/2015/07/ conar-absolve-boticario-por-propaganda-com-casais-gays.html>. Acesso em: 28 abr. 2017.

G1. Comercial de O Boticário com casais gays gera polêmica e chega ao Conar, 2015. Disponível em: <http://g1.globo.com/economia/midia-e-marketing/noticia/2015/06/comercial-de-o-boticario-com-casais-gays-gera-polemica-e-chega-ao-conar.html>. Acesso em: 28 abr. 2017.

G1. Brasil é o país que mais mata travesties no mundo, diz pesquisa, 2017. Disponível em: $<$ http:/ / g1.globo.com/profissao-reporter/noticia/2017/04/brasil-e-o-pais-que-mais-mata-travestis-e-transexuais-no-mundo-diz-pesquisa.html > . Acesso em: 28 abr. 2017.

IBGE. Censo Demográfico Brasileiro. 2010. Disponível em: < http:/ / censo2010.ibge.gov. br/ > . Acesso em: 28 abr. 2017.

KIELING, A. P.; HOFFMANN, E. M.; BOEING, R. Abocanhando o Mercado: O Caso da Rock Hamburgueria. Administração: Ensino e Pesquisa. v. 18, n. 1, p.153-186. Jan-Abr 2017.

KONDO, E. K. et al. Marketing de Relacionamento e Estratégias de Fidelização de Clientes Pessoas Físicas. Revista ANGRAD, v. 10, n. 3. 2009.

KOTLER, P.; KELLER, K. L. Administração de marketing. São Paulo: Pearson Prentice Hall, 2006.

KOTLER, P.; KELLER, K. L. Administração de marketing - 14.ed. São Paulo, SP: Pearson Education do Brasil, 2012.

MEIO E MENSAGEM. Personagem gay ainda choca: Estudo da J.W. Thompson indica que população não está preparada para aceitar casais homossexuais na publicidade. Revista Meio e Mensagem, São Paulo, set. 2014. Disponível em: <http:/ /www.meioemensagem. com.br/home/comunicacao/-0001/11/30/personagem-gay-ainda-choca.html > . Acesso em: 24 abr. 2016.

MOWEN, J. C.; MINOR, M. S. Comportamento do consumidor. São Paulo: Prentice Hall, 2003.

O BOTICÁRIO. Campanha Dia dos Namorados 2015. Youtube. Disponível em: <https:// www.youtube.com/watch?v=p4b8BMnolDI>. Acesso em: 17 jan. 2018.

OAKENFULL, G. K.; GREENLEE, T. B. Queer eye for a gay guy: Using market-specific symbols in advertising to attract gay consumers without alienating the mainstream. Psychology \& Marketing, v. 22, n. 5, p. 421-439, 2005. 
OAKENFULL, G.; McCARTHY, M. S.; GREENLEE, T. B. Targeting a minority without Alienating the Majority: Advertising to Gays and Lesbians in Mainstream Media. Journal of Advertising Research, p. 191-198, 2008.

OGDEN, J. R.; CRESCITELLI, E. Comunicação integrada de marketing: conceitos, técnicas e práticas. 2. ed. São Paulo: Prentice Hall do Brasil, 2007.

OLIVEIRA, J. A. A publicidade rende-se à diversidade sexual: um estudo de recepção sobre a campanha 'Casais' do perfume Egeo de O Boticário. In: $38^{\circ}$ CONGRESSO DE CIÊNCIAS DA COMUNICAÇÃO, Rio de Janeiro, 2015. Anais... Rio de Janeiro: Intercom, 2015.

PEÑALOZA, L. "We're here, we're queer, and we're going shopping”: A critical perspective on the accommodation of gays and lesbians in the U.S. marketplace. In: Wardlow, D. L. (Ed.). Gays, lesbians, and consumer behavior: Theory, practice, and research issues in marketing. New York: Haworth Press, 1996. p. 9--42.

RODRIGUES, J. L. P.; VICTORIO FILHO, A. Os anúncios na imprensa gay do Brasil. In: IV ENCONTRO DE ESTUDOS MULTIDISCIPLINARES EM CULTURA, Salvador, 2008. Anais... Salvador: Enecult, 2008.

SOUSA, I. Mercado é cego para potencial de consumo do público LGBT. Revista Exame, São Paulo, v.1021, 2012.

UM, N. Does gay-themed advertising haunt your brand?. International Journal of Advertising. v. 33, n. 4, p. 811-832, 2014. 


\section{ANA PAULA KIELING}

\section{DADOS DOS AUTORES}

\section{ESTELA MARIA HOFFMANN` estelamhoff@gmail.com}

\section{Doutoranda em Administração pela UNIVALI}

Instituição de vinculação: Universidade do Vale do Itajaí

Biguaçu/SC - Brasil

Áreas de interesse em pesquisa: Marketing; Comportamento do Consumidor; Estratégias em Marketing; Comunicação.

^ Rua João Coan, 400 - Bloco I, sala 101 Bairro Universitário Biguaçu/SC 88161-064

\section{MARIA JOSÉ BARBOSA DE SOUZA mjbsouza2@gmail.com}

Doutora em Ciências da Comunicação pela USP/ECA

Instituição de vinculação: Universidade do Vale do Itajaí

Biguaçu/SC - Brasil

Áreas de interesse em pesquisa: Marketing; Comportamento do Consumidor;

Responsabilidade Social.

\section{ANA PAULA KIELING anakieling@gmail.com}

\section{Doutoranda em Administração pela UNIVALI}

Instituição de vinculação: Universidade do Vale do Itajaí

Biguaçu/SC - Brasil

Áreas de interesse em pesquisa: Marketing; Comportamento do Consumidor. 